\title{
MUNA ON / EI OLE TARGEM KUI KANA
}

\section{Vastuolulised vanasõnad}

\author{
RISTO JÄRV
}

$\mathrm{E}$ lu ebamäärasuses aitavad suunda seada kindlad tõdemused. Üks selliseid esinduslikke elutarkuse liike on vanasõnad. Õigel hetkel tarvitatuna on need ütlused justkui veenev argument, millele pole paslik vastu vaieldagi. Oma vanasõnasaadetises Jakob Hurdale on Tartumaalt Kursi kihelkonnast pärit sulane Jaan Pruuli 1889. aastal kirja pannud hulga selliseid kindlaväitelisi konstruktsioone, nagu „Kes kannatab, see kaua elab. Kes järele jätab, see saab järje piale. Ei kahe talu koer saa elades süüa. Häda ajab härja kaevu. Kel janu, sel jalad" (H III 8, 105 (8-12)). Ja siis korraga seisab vanasõnaloendis üllatuslik ühend: „Muna on (pole) targem kui kana” (H III 8, 105 (13)).

Kuigi esmahetkel kõlab see jaaeitus kui näide valikvastustega testist, tundub sulgude tekitatud dihhotoomia väljendavat midagi enamat. Loendi muude vanasõnade kontekstis paistab kirjapanek viitavat Jaan Pruuli teadmusele, et käibibki kaks vastandlikku kana ja muna tarkust võrdlevat vanasõna. Eesti Kirjandusmuuseumi Eesti Rahvaluule Arhiivi ainese põhjal registreeritud vanasõnatüüpide hulgas esineb nii seisukoht „Muna ei ole targem kui kana” (tüübinumber eesti vanasõnade akadeemilises väljaandes EV 6902) kui ka sellele pealtnäha otse vasturääkiv „Muna on targem kui kana” (EV 6901).

Vanasõnade vastuolulisuses pole midagi ebaharilikku. Sama monumentaalväljaande I köite mahukast sissejuhatusest leiab lõigu selle kohta, et igas vähegi ulatuslikumas vanasõnakorpuses ilmneb „üksteisele vasturääkivate väidete, hinnangute ja imperatiivide rohkus. Nende vastuolude algallikaks on muidugi igapäevane elupraktika ise, mis valikut võimaldavaid või nõudvaid probleemisituatsioone igal sammul välja pakub". (EV I: 54) Kuidas siis saada selgust, mida eestlased on pigem arvanud, kumb on esivanemate arvates tark - muna või kana? Kõige lihtsam tunduks statistika: vaatame, mitu arvamust esindab kumbagi seisukohta ehk mitu varianti on kummastki vanasõnatüübist talletatud. V a n a sõnadele iseloomulik suundumus väärtustada pigem esiv a n e maid eeldaks justkui, et emal on tarkust enam, kuid statistika purustab sellise ootuse: „muna-ei-ole-targem” seisukoht on väljaandes esindatud kõigest 11 rahvaehtsaks loetud variandiga, „muna-on-targem” aga suisa 105 variandiga. Akadeemilises väljaandes on esitatud kokkuvõtlikult ka põhilised tekstiredaktsioonid, täistekstidega tutvumiseks pöördume kirjandusmuuseumi arhiivikartoteekide juurde. Sedelite läbilappamine on hea püsivuse meeleharjutus, sellest kujuneb suisa hüpnootiline kogemus: järelejätmatult seisab kartoteegikaardil väikeste variatsioonidega sama tekst „Muna on targem kui kana”, siis „Muna targem kui kana”, setukeelne „Muna om targõmb ku kana”, sekka kahtlust tekitav vastupidine „Muna nüüd targem kui kana”, siis taas kinnitus „Muna ikka targem kui kana”. Nii jäädki uskuma, et asi 
ants - muna on targem kui kana. Vaid vahetevahel katkestavad seda monotoonset mantrat mõned selgitused, mida rahvaluule kirjapanijad on aegade jooksul vajalikuks pidanud vanasõnade juurde lisada. Viimaseid pole palju, kümmekonnal juhul on kirjapanija lisanud sellele vanasõnale kommentaari. Neist saame aga aimu, et seda ütlust võiks võtta hoopis iroonilisena. Nii on vennad Jaan ja Peeter Einer Helme kihelkonnast Jõgevestelt 1880. aastate lõpus üles tähendanud: „Üteldakse halvale lapsele, kes vanemate nõu heaks ei kiida" (H II 24, 582 (45)). Emilie Poom Märjamaa kihelkonnast on seda vanasõna selgitanud mitmes oma saadetises, viimati aastal 1956: „Öeldi siis, kui laps tahtis ema õpetada” (RKM II 58, 43 (32)). Arnold Piir on 1957. aasta kirjapanekus Rannu kihelkonnast lisanud: „Irooniline ütlus ninakate noorte kohta” (RKM II 71, 200 (46)). Või on see lihtsalt märgitud manitsuseks lapsele, „kui see end vanemate jutusse segab" (ERA II 209, 343 (12)).

Võiks ju oletada, nagu olekski rahvapärane iroonia variantide arvu nii kõrgeks ajanud - ja et ehk ongi Jaan Pruuli sulukonstruktsioon „on (pole)” hoopis napp teadaandmine, et on tähendab 'ei ole'. Asi on aga keerulisem: arhiivi selgitustest leiame mõne kinnituse, et „muna-on-targem”-varianti on võetud siiski tõemeeli. Jaak Sõggel Saarde kihelkonnast on 1937. aastal märkinud: „Üteldakse, kui mõni laps mõnda enam mõistab, kui ema või teine vana inimene" (ERA II 181, 43 (27)). Valga kooli õpilane, hilisem kirjanik Jaak Sarapuu on 1956. aastal lisanud vanasõnale kommentaari: „Öeldakse, kui laps teab head nõu anda" (RKM II 49, 590 (38)). Viimase peale võib muidugi kulmu kergitada, et selgitaja on ju ka ise opilane - ehk ilmsesti ise erapoolik. Ometi võivad paljud vanemad sellega ehk nõustuda, et lastele võib alla jääda mitte ainult gümnaasiumi koolitarkuses ja tehnikateadmuses, vaid näiteks kas või vaatenurga värskuses.

Ka kommentaarideta vanasõnadest võib välja lugeda pooltoone. Andres Juurikas Tori kihelkonnast on 1889. aastal sedastanud: „Muna on vahest targem kui kana" (H II 21, 706 (7), minu rõhutus - R. J.). Või siis 1869. aastal tehtud koolmeister Jüri Petersoni kirjapanek: „Muna tahab kanast targem olla" (EKmS 4², 666 (57)). (See ei käinud ilmselt seega ta aasta hiljem sündinud poja, meile tuntud kirjaniku Ernst Peterson-Särgava kohta!) Põllumees Aleksander Eduard Vaas Iisaku kihelkonnast seevastu selgitab 1889. aasta üleskirjutuses: „Muna on i kke targem kui kana” (H I 10, 40 (41), minu rõhutus $-R$. J.). Oma mõju selle vanasõnatüübi populaarsusele meie keeleruumis on andnud ilmselt pikk ajalooline traditsioon: eestikeelne kirjapanek esineb juba Anton Thor Helle 1732. aasta eesti keele grammatikas ning Beiträges (III, 1817) on ära toodud ladinakeelse vastena "Ovum prae gallina sapit”. Wiedemann oma teoses „Aus dem inneren und äusseren Leben der Ehsten” (1876: 126) esitab sulgudes elliptilise lause: „muna (tahab) targem (olla) kui kana”, lisades saksakeelse selgituse „das Ei will klüger sein als die Henne”.

Teadlane teab, et järeltulija peab olema - viimakski - targem kui eelkäija. Folklorist Ellen Liiv on 1947. aastal Juuli Liivalt Püha kihelkonnas üles kirjutanud selgituse, miks muna on „ikka targem kut kana”: ,järgnev põlvkond on eelnevast targem" (RKM II 24, 415 (47)). Igal juhul tundub olemasoleva põhjal, et vanasõna „Muna on targem kui kana" kasutus on teadaolevate andmete põhjal ambivalentne, rõhk on aga pigem iroonilisel seisukohal, eriti hilisemal perioodil. 
Märksa üheplaanilisem on kartoteegis järgmise tüübiga 6902 - „Muna ei ole targem kui kana" - seonduv kommentaariosa. Siin pole olnud midagi seletamisväärset, kõik need 11 üleskirjutust on ilma selgituseta nendingud, et muna ei ole targem kui kana. Tervikküsimuse lahendamatusest annab aimu seegi.

Siinkohal paar lahtiütlust. Esmalt: rahvaluulekogumise käigus saadud vanasõnaarvud on mõistagi osalt juhuslik suurus. Mis tahes vanasõna üleskirjutuste arv ei tarvitse näidata seda, kui palju seda tegelikult on teatud, kuigi üldtendentsi siiski. Teiseks, mis tahes siin toodud vanasõnaarv peegeldab Eesti rahvaluulekogude seisu 1980. aastate eel, kui vanasõnade akadeemilise väljaande käsikiri hakkas valmis saama ja sellele oli eelnenud tüpoloogilise kartoteegi korrastustöö. Materjalikogumeid korraldavate folkloristide tegevuse väljaandepõhine finantseerimine on tinginud selle, et värskeid vanasõnu sellest tüpoloogiakogumist ei leia ja tulebki toetuda põlvkonnataguse publikatsiooni arvandmetele. Kolmandaks, kogutud vanasõnaainese tüüpidesse jagamine vanasõnauurijate poolt on olnud niikuinii kokkuleppeline ning otsustused pole sugugi alati veenvad olnud. Ehk tunduks meile pilt hoopis teine, kui iroonilised vanasõnad oleks viidud hoopis „kana-munast-targem”tüübi EV 6902 alla. Või miks mitte hoopis kolmanda, vanasõnatüübi „Ega muna kana ei õpeta" (EV 6891, 7 varianti) hõlma. Ja viimaks: vanasõnadele ongi ju tunnuslik deskriptiivne määramatus, mõistukõne mitmeti tõlgendatavus (VSR 1984: 566). Seega on tõde niikuinii oletuslik.

Kindlasti võib sama sõnastust kasutada erinevates (isegi vastandlikes) situatsioonides, seepärast tuleb rõõmu tunda nende väheste rahvaluulekirjapanekute üle, kus kirjapanija on lisanud, mida tema arvates ühe või teise ütlusega on mõeldud. Kui tegime vanasõnu selgitavat väljaannet „Kes otsib, see leiab. 1111 eesti vanasõna selgituste ja kommentaaridega" (1111 vanasõna), ei olnud kolm autoritki alati ühel meelel, milline vanasõnaseletus arhiiviseletustest sisse võtta või kas autori enda kui samuti rahva esindaja tõlgendus välja tuua, kui sarnast arhiivis olnud seisukohtade seast ei leia - mahu tõttu sai esitada kõige rohkem paar seletust. Alati ei ole kõik nii selge kui näiteks sellise tuntud vanasõna puhul nagu „Magaja kassi suhu ei jookse hiir” (EV 6297), millele on olemas kõhetum antagonist: „Magajale kassile jooseb vahest ka hiir suhu" (EV 6296). (Esimest on registreeritud 230, teist 14 varianti, nii et variantide erinevus on siin veelgi kõnekam.)

Viimane, justkui mitte usinat protestantlikku tööeetikat kuulutav seisukoht paneb küsima, kas peaksime propageerima seisukohti ja vanasõnu, mida ise ei usu, või veelgi enam, koguni õigeks ei pea. Kui kana munast muidu jagu ei saa, kas on tänapäeval kasvatusmeetodina sobilik vanasõna „Mida armsam laps, seda kibedam vits" (EV 367, 175 varianti)? On hulk selliseid vanasõnu, mida võime pidada suisa demoraliseerivaks. (Veel) tsensuurivabas ühiskonnas tekib küsimus teadlase enesetsensuurist eeskujuviisina: kui avaldame ja teeme kättesaadavaks vanasõnavalimikke eesti rahvaluule osana, siis kas on ikka hea kirjutada mustvalgel, et meie vanasõnavaramu tüübitekstina esineb näiteks „Kui ei ole surmatõbi, siis saab ikka viinast abi” (EV 10772, 30 varianti)? Või ebaausust õhutav proverbipaar „Parem ikka vähe kelm kui suur aus olla” (EV 3582) ning „Varasta, aga mitte nõnda, et üles tuleb” (EV 13779, mõlemat 5 varianti)? Regionaalpoliitilises kontekstis mõjub ehmatavalt 
selline, ilmselt alliteratsioonist tingitud lokaliseering, nagu „Narr, kes Narvast naise võtab, loll, kes linnast lehma ostab” (EV 7386, 11 varianti). Võõravihale valab õli tulle valdavalt lõunaeestiline tüüp „Paremb um uma oline ku võõras villane” (EV 8005, 11 varianti), veeks koduvägivalla veskitele on vanasõnatüüp „Naist võib nii kaua peksada, kui tulelt võetud kördipada maas veel keeb” (EV 7313, 8 varianti). Laulu- ja tantsupeoaastale kohatu tundub „Ega leelost leiba saa, ega laul kata lauda” (EV 5623, 10 varianti) ning „Põrgu lähevad pillilööjad, tantsijad taga järele" (EV 206, 6 varianti) jne. Nii jääks mõnegi arvates folkloorile külge konnotatsioon „vale”, mida aga rahvaluule kindlasti pole. On ilmselge, et just selline intrigeeriv ainestu võib pälvida (sotsiaal)meedia tähelepanu palju enam kui tavaline didaktiline rahvatarkus. Kui sellistel puhkudel domineerivat ei märgata, vaid hakatakse esile tooma just selliseid, põhilisest põikuvaid suundumusi, poleks see kuigi rõõmustav meie tõejärgses ühiskonnas. Kas see tähendaks, et peaksimegi sellised „mittekõlbelised” vanasõnad kõlbmatuks kuulutama ja jätma vaid akadeemiliste väljaannete ossa või on võimalik ning vajalik jätkuvalt avaldada neid ka rahvaväljaannetes?

Folklorist Oskar Loorits on oma inspireerivas essees „Muinaseesti unarusse jäänud põhiseadusest" (2000 [1938]) käsitlenud eesti vanasõnu poleemikas Eesti põhiseaduse loomise üle. Looritsa põhjal on õigussotsioloog Aare Kasemets (2007: 90-91) koondanud väljatoodud põhimõtted paragrahviloendisse:

$\S$ 1. Nõu ja mõistuse põhimõte (nt Looritsal vanasõnad „Nõu on ülem kui jõud”, „Noored jõule, vanad nõule”).

§ 2. Õiguse põhimõte (nt „Õigus on üle kõige”, „Õiguse vastu ei saa ükski”).

$\S 3$. Vankumatu tõemeele põhimõte (nt „Tõde tõuseb, vale vajub”, „Vale on varguse ema").

$\S 4$. Au ja aususe põhimõte (nt „Aus meel käib üle kõige”, „Parem aus nimi kui suur rikkus").

Kui keegi tahaks eesti vanasõnavaramust kiuslikult esile tuua teistsugust meelsust, võiks konstrueerida hoopis teisipidised põhipunktid, ent samuti kõigiti ausalt eesti vanasõnade põhjal. Nii võiks nood hüpoteetilised provotseerijad öelda, et arvestatav hulk arvajaid on olnud veendunud eestlasele omane olevat:

§ 1. Kahtleva mõistuse põhimõte (vrd vanasõna „Ära usu ilma, ilm ajab puru silma”, EV 12957, 115 varianti).

$\S$ 2. Rikkama õiguse põhimõte („Kel vägi, sel võimus, kel kukkur, sel kohus", EV 14434, 100 varianti).

$\S 3$. Praktilise tõemeele põhimõte (nt „Kes huntide hulkas on, peab nendega uluma", EV 1654, 85 varianti).

$\S$ 4. Targa kelmuse põhimõte (nt „Natuke valetada, natuke varastada änam kut poole adra puumaa", EV 7403, 45 varianti).

Tõsi, Loorits mainib ka ise selliseid vastandlikke suhtumisi, viidates, et vanasõnas valetamisest ja varastamisest „ei anta veel mingit retsepti ega reeglit, kuidas peaks elatama, vaid konstateeritakse ainult ebameeldivat 
fakti, kuidas tegelikult sageli tõepoolest elatakse" (Loorits 2000: 266). Siiski ei saa olla selles nii kindel, vanasõnadest on keeruline tuletada ühtset maailmavaatelist süsteemi. Kuigi Arvo Krikmanni kinnitusel selliste vasturääkivate vanasõnade puhul tavaliselt "tugevam alternatiiv on esindatud tõsiseltvõetavate lausetega, nõrgem aga peamiselt vanasõnavormiliste naljasõnadega" (Krikmann 1997: 278), pole see modaalsus sugugi alati ilmselge, sest konteksti me tavaliselt ei tea.

Oma selleteemalises essees „Kas vanasõnad on vastuolulised?” on Ghana vanasõnauurija Kwesi Yankah (1994 [1984]) rõhutanud, et vanasõnaüleskirjutustes on oluline kontekstuaalsus, nende sotsiaalne kontekst: inimesed ei räägi vastandlike vanasõnadega, konkreetses kasutussituatsioonis ongi vanasõnad kõik õiged. See ei räägi sugugi vastu põhimõttele „Vanasõna ei valeta” (EV 13585, 25 varianti), sellega tuleb leppida ning vanasõnu kasutada - vajadusel kas või vastamisi ristates. Vanasõnal on küll alati õigus, kuid vanasõna õigsus sõltub kontekstist, sellest, millisel hetkel teda kasutatakse. Nii märgib ka Loorits oma essee lõpus, et vanasõnad ,jätavad igale vabaduse ise valida, missugust teed keegi tahab elus käia" (Loorits 2000: 271).

Vanasõnad, nagu rahvaluule tervikuna, on arvamuste paljusus, valikuvabadus. Eesti, nagu teiste rahvaste folklooris on leidnud elujõudu erinevad vanasõnad, mis vastastikku üksteisega polemiseerivad, leides kasutust alates argielust kuni poliitretoorilise kõrgpilotaažini välja. Sõltuvalt olukorrast võib sobida üks või teine, kuid kindlasti tuleb soovida jätkuvat tarkust ja tervet meelt nende tarvitamisel - nii kanadele kui ka munadele.

Mõlgutuse valmimist on hõlbustanud Haridus- ja Teadusministeerium (IUT 22-4 „Folkloor kultuurilise kommunikatsiooni protsessis: ideoloogiad ja kogukonnad”) ning Euroopa Liit Euroopa Regionaalarengu Fondi kaudu (Eesti-uuringute Tippkeskus).

\section{Arhiiviallikad}

EKM ERA - Eesti Kirjandusmuuseumi Eesti Rahvaluule Arhiiv

EKmS - Eesti Kirjameeste Seltsi rahvaluulekogu

ERA - Eesti Rahvaluule Arhiivi rahvaluulekogu

$\mathrm{H}$ - Jakob Hurda rahvaluulekogu

RKM - Riikliku Kirjandusmuuseumi rahvaluulekogu

\section{Kirjandus}

$\mathrm{EV}=$ Eesti vanasõnad I. (Monumenta Estoniae Antiquae 2. Proverbia Estonica 1.) Toim A. Krikmann, I. Sarv. Koost A. Hussar, A. Krikmann, E. Normann, V. Pino, I. Sarv, R. Saukas. Tallinn: Eesti Raamat, 1980.

Ka s e m ets, Aare 2007. Looduslike pühapaikade kultuuri- ja looduspärandi kooshoidmine: jätkusuutlikkuse eeldused. - Looduslikud pühapaigad. Väärtused ja kaitse. (Õpetatud Eesti Seltsi toimetised 36.) Koost Ahto Kaasik, Heiki Valk. 
Toim H. Valk. Tartu: Maavalla Koda, Tartu Ülikool, Õpetatud Eesti Selts, lk 77-128.

Krikmann, Arvo 1997. Sissevaateid folkloori lühivormidesse I. Põhimõisteid, žanrisuhteid, üldprobleeme. Tartu: Tartu Ülikooli Kirjastus.

Loorits, Oskar 2000 [1938]. Muinaseesti unarussejäänud põhiseadusest. O. Loorits, Meie, eestlased. (Eesti mõttelugu 35.) Tartu: Ilmamaa, lk 260-276.

1111 vanasõna $=$ Piret Voolaid, Risto Järv, Loone Ots, Kes otsib, see leiab. 1111 eesti vanasõna koos kommentaaridega. Tallinn: Rahva Raamat, 2018.

VSR = Anne Hussar, Arvo Krikmann, Ingrid Sarv, Vanasõnaraamat. Tallinn: Eesti Raamat, 1984.

Yankah, Kwesi 1994 [1984]. Do proverbs contradict? - Wise Words. Essays on the Proverb. Toim Wolfgang Mieder. (Routledge Library Editions: Folklore.) London-New York, lk 127-142.

Risto Järv (snd 1971), PhD, Eesti Kirjandusmuuseumi Eesti Rahvaluule Arhiivi juhataja (Vanemuise 42, 51003 Tartu); Tartu Ülikooli kultuuriteaduste instituudi eesti rahvaluule dotsent, risto.jarv@folklore.ee

\section{The egg is (not) teaching the hen: controversial proverbs}

Keywords: proverbs, truth, lie, proverbial wisdom

The Estonian Folklore Archives at the Estonian Literary Museum contains 105 recordings of proverbs of the type "The egg is teaching the hen" (EV 6901) and only 11 of the type "The egg cannot teach the hen" (EV 6902). Still, the relative proportions need not imply actual predominance of the former view in the proverbial wisdom: although some of the proverbs of the former type have been recorded all in earnest, some have been registered in an ironic sense, but for a number of the latter kind no such specification is available. This proves that even the uses of one and the same proverb can vary. The proverb is always right, but that rightness depends on the context and moment of its use. Thus, there is an inherent plurality and freedom of choice when it comes to proverbs, and folklore in general. Folklore features various proverbs that engage in vigorous polemics with one another, while the fields in which they are used range from daily life to highly skilled political rhetoric.

Risto Järv (b. 1971), PhD, Estonian Folklore Archives of the Estonian Literary Museum, Head of the Archives (Vanemuise 42, 51003 Tartu); University of Tartu, Department of Estonian and Comparative Folklore, Associate Professor of Estonian Folklore,risto.jarv@folklore.ee 